\title{
Characterization of regulatory elements on the promoter region of human ATP-citrate lyase
}

\author{
Young-Ah Moon', Kyung-Sup Kim ${ }^{1}$, \\ Un-Hyung Cho', Do-Jun Yoon ${ }^{2}$ and \\ Sahng-Wook Park ${ }^{1,3}$ \\ 1 Department of Biochemistry and Molecular Biology, Institute of Genetic Science, \\ Yonsei University College of Medicine, Seoul 120-752, Korea \\ 2 Department of Biochemistry, Kwandong University College of Medicine, Kangnung, \\ 210-701, Korea \\ 3 Corresponding author: Phone, 0391-649-7465; Fax, 0391-641-1074; E-mail, \\ swpark64@mail.kwandong.ac.kr
}

Accepted 18 May 1999

Abbreviations: ACL, ATP-citrate lyase; CAT, chloramphenicol acetyl transferase; MEM, minimal essential medium; PBS, phosphate-buffered saline; FBS, fetal bovine serum, SDS; sodium dodecyl sulfate, PAGE; polyacrylamide gel electrophoresis.
Keywords: ATP-citrate lyase, promoter, Sp1, Sp3, lipogenesis, glucose

\section{Introduction}

Aceytl moiety of the acetyl-CoA is transferred to oxaloacetate in mitochondria to form citrate, which is transferred to cytosol via tricarboxylate transporter, where it is recleaved into oxaloacetate and acetyl-CoA, and utilized in the biosynthesis of fatty acid and cholestrol. ATPcitrate lyase $(A C L)$ is a cytosolic enzyme that catalyzes a cleavage of citrate into oxaloacetate and acetyl-CoA (Kornacker and Lowenstein, 1965). The expression of this enzyme is regulated at transcription level by fasting/ refeeding regimen when the need for lipogenesis changes (Kim et al., 1992a). This regulation of enzyme expression is very similar to that of other lipogenic enzymes, such as fatty acid synthase (Katsurada et al., 1990a; Kim et al., 1992b) and acetyl-CoA carboxylase (Katsurada et al., 1990b). Recently, the 5' flanking regions of ACL gene in human has been cloned (Park et al., 1997). The sequences in the promoter of this gene is highly conserved between human and rat (Kim et al., 1994), even though there is no homology in regions of the 5' UTR and first intron, suggesting that the regulation at transcription level takes place in the same manners in these two species. Clinically, $\mathrm{ACL}$ is thought to be a potential target for hypolipidemic intervention, because the specific inhibition of this enzyme in rats significantly decreased the plasma levels of cholesterol and triacylglycerol (Pearce, et al., 1998). Since ACL plays an important role in lipogenesis, the regulation of many transcription factors, e.g., peroxisome proliferator-activated receptors, sterol regulatory element binding proteins, and NF-Y, which mediate the expression of genes related to lipogenesis are under investigation. Although an importance of the role of $A C L$ is not under-estimated, only a few studies on the transcriptional regulation of the $A C L$ promoter are reported.

In this paper, we investigated the primary structure of the ACL promoter, focusing on the binding sites for transcription factors in the core promoter region. Based on the DNA sequence analysis, Sp1 family transcription factors were the primary target of investigation, in order to show their potential contribution to ACL expression under the condition of enhanced lipogenesis.

\section{Materials and Methods}

\section{Cell culture}

Alexander cells (PLC/PRF/5, ATCC) were cultured in 
minimal essential medium (MEM) supplemented with 10 $\%$ fetal bovine serum (FBS), 100 unit $/ \mathrm{ml}$ penicillin $\mathrm{G}$ sodium, $100 \mu \mathrm{g} / \mathrm{ml}$ streptomycin sulfate, and $0.25 \mu \mathrm{g} / \mathrm{ml}$ amphotericine B. All cell culture materials were purchased from Life Technologies, Inc (Gaithersburg, MD, USA). When glucose induction was tested, the culture media were changed with RPMI medium 1640 lacking glucose 2 days prior to experiment, then cells were incubated with medium containing $25 \mathrm{mM}$ glucose.

\section{Construction of the ACL promoter- chloramphenicol acetyl transferase plasmids}

ACL promoter-CAT reporter constructs were prepared in pCAT3-basic (Promega) vector using Exonuclease III nested-deletion kit (Amersham Pharmacia Biotech), as described by Park et al. (1997), or using PCR amplification with the respective primers. The each ACL promoter-CAT construct contains the ACL promoter region spanning 321 to +440 (phACL-321), -213 to +440 (phACL-213), 127 to +440 (phACL-127), -82 to +440 (phACL-82), -75 to +440 (phACL-75), and +13 to $+440(\mathrm{phACL}+13)$. The sequences of all constructs were confirmed with the T7 sequencing kit (Amersham Pharmacia Biotech).

\section{Transient DNA transfection}

All plasmid used for transfection were purified by Qiagen Plasmid Midi Kit (QIAGEN Inc.). Typically, Alexander cells were seeded in 6-well plates at a density of $2 \times 10^{5}$ cells per well in MEM supplemented with $10 \%$ FBS. For an assay of basal promoter activity, the components of culture media were all same through entire processes of experiment. For the experiment evaluating effects of glucose supplementation on the ACL promoter, the culture condition was modified as follows. When the cells were grown to $70 \%$ level of confluency of well, the culture media were changed with RPMI medium 1640 containing $10 \%$ FBS. On the following day, cells were washed with the phosphate-buffered saline (PBS; Life Technologies, Inc.), and then the media were changed with RPMI medium 1640 lacking glucose and serum. Instead of serum, supplements (Life Technologies, Inc.) were added to enhance survival of cells. Two days after changing the media, cells were washed twice with PBS, and added Opti-MEM without serum. For each well of culture plate, $0.5 \mu \mathrm{g}$ of indicated reporter constructs were transfected using Lipofectin reagent (Life Technologies, Inc.) according to the manufacturer's instruction. After 6 $\mathrm{h}$ of transfection, cells were washed twice with PBS and then added RPMI medium 1640 lacking glucose. For the induction group, the media were supplemented with $25 \mathrm{mM}$ glucose. After $48 \mathrm{~h}$ of culture, cells were washed with PBS and harvested in $500 \mu \mathrm{l}$ of $0.25 \mathrm{M}$ Tris- $\mathrm{HCl}$ buffer, $\mathrm{pH}$ 7.8. The cell extracts were prepared by three freeze-thaw cycles. Aliquots of $20 \mu \mathrm{l}$ of cleared lysate in the same amount of proteins were assayed for CAT activity using $\left[{ }^{14} \mathrm{C}\right]$-chloramphenicol by thin-layer chromatography.

\section{Preparation of nuclear extract}

Nuclear extracts from the cultured Alexander cells were prepared as described by Dignam et al (1983). Briefly, $10^{8}$ Alexander cells were broken in a Dounce homogenizer (10 strokes) in a 5-fold packed cell pellet volume of 10 $\mathrm{mM}$ Hepes buffer, $\mathrm{pH} 7.9$, containing $1.5 \mathrm{mM} \mathrm{MgCl}_{2}, 10$ $\mathrm{mM} \mathrm{KCl}, 0.5 \mathrm{mM}$ dithiothreitol, $0.5 \mathrm{mM}$ phenylmethylsulfonylfluoride, and protease inhibitors mixture containing $20 \mu \mathrm{M}$ leupeptin, $20 \mu \mathrm{M}$ pepstatin, and $2 \mu \mathrm{M}$ aprotinin. The nuclear pellet was then resuspended in $0.3 \mathrm{ml}$ of 20 $\mathrm{mM}$ Hepes buffer, pH 7.9, containing 25\% glycerol, 1.5 $\mathrm{mM} \mathrm{MgCl}_{2}, 0.2 \mathrm{mM}$ EDTA, $420 \mathrm{mM} \mathrm{NaCl}, 0.5 \mathrm{mM}$ dithiothreitol, $0.5 \mathrm{mM}$ phenylmethylsulfonylfluoride, and protease inhibitors. Nuclei were allowed to swell for 30 min at $4^{\circ} \mathrm{C}$ with gentle stirring and clear nuclear extracts were obtained by centrifugation at $25,000 \mathrm{~g}$ for $30 \mathrm{~min}$ at $4^{\circ} \mathrm{C}$. The supernatant fractions were dialyzed against 50 volumes of the same buffer for $5 \mathrm{~h}$. The dialysates were freed of debries by centrifugation at $25,000 \mathrm{~g}$ for $20 \mathrm{~min}$ and the clear fractions were aliquoted and stored at $-70^{\circ} \mathrm{C}$ until required. The amount of nuclear proteins were measured by the method of Bradford et al. (1976) and the integrity of the nuclear protein preparations in the control and the glucose-induced groups were examined by SDS-PAGE.

\section{Gel mobility shift assay}

Nuclear proteins were incubated with ${ }^{32} \mathrm{P}$-end-labeled DNA fragment of the ACL promoter $(20,000 \mathrm{cpm})$ in a $20 \mu \mathrm{l}$ reaction mixture of $17.5 \mathrm{mM}$ Hepes buffer, $\mathrm{pH}$ 7.6, containing $80 \mathrm{mM} \mathrm{KCl}, 0.7 \mathrm{mM}$ EDTA, 10\% glycerol, $0.035 \%$ Triton X-100, $1 \mathrm{mM}$ dithiothreitol, and $1 \mu \mathrm{g}$ poly (dl-dC) (Amersham Pharmacia Biotech), for 30 min on ice. For supershift or competition assay, antibodies against human Sp1 or unlabeled competitors, respectively, were preincubated with the nuclear extracts for $30 \mathrm{~min}$ in the same buffer before adding the probes. The binding reaction was resolved on a $5 \%$ polyacrylamide gel in $50 \mathrm{mM}$ Tris buffer, $\mathrm{pH}$ 8.2, containing $130 \mathrm{mM}$ glycine, and $1 \mathrm{mM}$ EDTA. The gels were pre-electrophoresed at $10 \mathrm{~V} / \mathrm{cm}$ for $2 \mathrm{~h}$ at $4^{\circ} \mathrm{C}$. Electrophoresis was performed at the same voltage for 2 to $3 \mathrm{~h}$ at $4{ }^{\circ} \mathrm{C}$. After electrophoresis, gels were briefly fixed in $5 \%(\mathrm{v} / \mathrm{v})$ methanol and $5 \%(\mathrm{v} / \mathrm{v})$ acetic acid, dried and subjected to autoradiography.

\section{DNase I footprinting}

The sense strand of the ACL promoter fragment was end-labeled at the BamHI site using Klenow DNA polymerase with $\left[\alpha-{ }^{32} \mathrm{P}\right] \mathrm{dATP}$ and $\left[\alpha^{32} \mathrm{P}\right] \mathrm{dCTP}(3000 \mathrm{Ci} /$ $\mathrm{mmol}$, Amersham). The fragment to be labeled was 
prepared by digestion of pACL-213 with Kpnl and $B a m \mathrm{HI}$, which generated the promoter fragment spanning from -213 to -17 from the transcription start site. Following labeling, the probe was isolated by nondenaturing poly-acrylamide gel electrophoresis. Binding assays were performed using $50,000 \mathrm{cpm}$ of labeled DNA and purified human Sp1 (Promega) for $20 \mathrm{~min}$ on ice in $50 \mu \mathrm{l} 10 \mathrm{mM}$ HEPES, pH 7.9 buffer containing, 75 $\mathrm{mM} \mathrm{KCl}, 1 \mathrm{mM}$ EDTA, $5 \mathrm{mM}$ dithiothreitol, $5 \mathrm{mM} \mathrm{MgCl}_{2}$, $10 \%$ glycerol, and $1 \mu \mathrm{g}$ of poly(dl-dC). DNA-protein complexes were treated with 1 unit of freshly diluted DNase I (Boeringer-Mannheim) and $50 \mu \mathrm{l}$ of $10 \mathrm{mM}$ $\mathrm{MgCl}_{2}$ and $5 \mathrm{mM} \mathrm{CaCl}_{2}$, for $2 \mathrm{~min}$ at room temperature. The digestion was stopped by adding $100 \mu$ l of reaction stop buffer containing 1\% (w/v) SDS, $200 \mathrm{mM} \mathrm{NaCl}, 20$ $\mathrm{mM}$ EDTA pH 8.0, and $0.1 \mu \mathrm{g} / \mu \mathrm{l}$ glycogen. The samples were phenol/chloroform-extracted, ethanol-precipitated, and resolved on an $8 \%$ denaturing polyacrylamide gel. Sequence analysis was done using sequence ladder of the same DNA fragment, obtained by the Maxam and Gilbert (1980) ' $G+A$ ' reaction procedure.

\section{Electrophoresis of nuclear extracts and immunoblot analyses}

SDS-PAGE of nuclear extracts was performed under reducing conditions according to Laemmli (1970). Fifty micrograms of proteins were combined with $5 \times$ SDSPAGE sample buffer; $0.3125 \mathrm{M}$ Tris- $\mathrm{HCl}, \mathrm{pH} 8.3$, con- taining 25\% $\beta$-mercaptoethanol, 50\% glycerol, and 0.5 $\mathrm{mg} / \mathrm{ml}$ bromophenol blue, and heated for $5 \mathrm{~min}$ at $100^{\circ} \mathrm{C}$. Samples were applied and gels developed at $40 \mathrm{~mA}$ for $1.5 \mathrm{~h}$. For Western blot analyses, proteins in SDSPAGE gels were electrotransferred to nitrocellulose membrane at $4^{\circ} \mathrm{C}$ overnight. Membranes were blocked with $5 \%$ non-fat dry milk in TBST buffer; $20 \mathrm{mM}$ Tris- $\mathrm{HCl}$, $\mathrm{pH} 7.5$, con-taining $500 \mathrm{mM} \mathrm{NaCl}$, and $0.1 \%$ Tween-20, and reacted with the indicated antibody (Santa Cruz Biotechnology, Inc.) followed by reaction with peroxidase-conjugated secondary antibody. Reaction products were visualized by reaction with ECL (Amersham Pharmacia Biotech) and exposure to x-ray film.

\section{Results}

\section{Activation of the ACL promoter by glucose}

In our previous study, we demonstrated that the proximal promoter for basal activity is confined to nucleotide -214 to +440 (Park et al., 1997). We reconstructed the ACL promoter-CAT reporter plasmids to localize more precise regions for basal promoter activity by nested deletion with exonuclease III or by PCR amplification with corresponding primers described in "Materials and Methods". Diagrammatic presentation of these constructs is shown in Figure 1. The transient transfection assay showed that the ACL
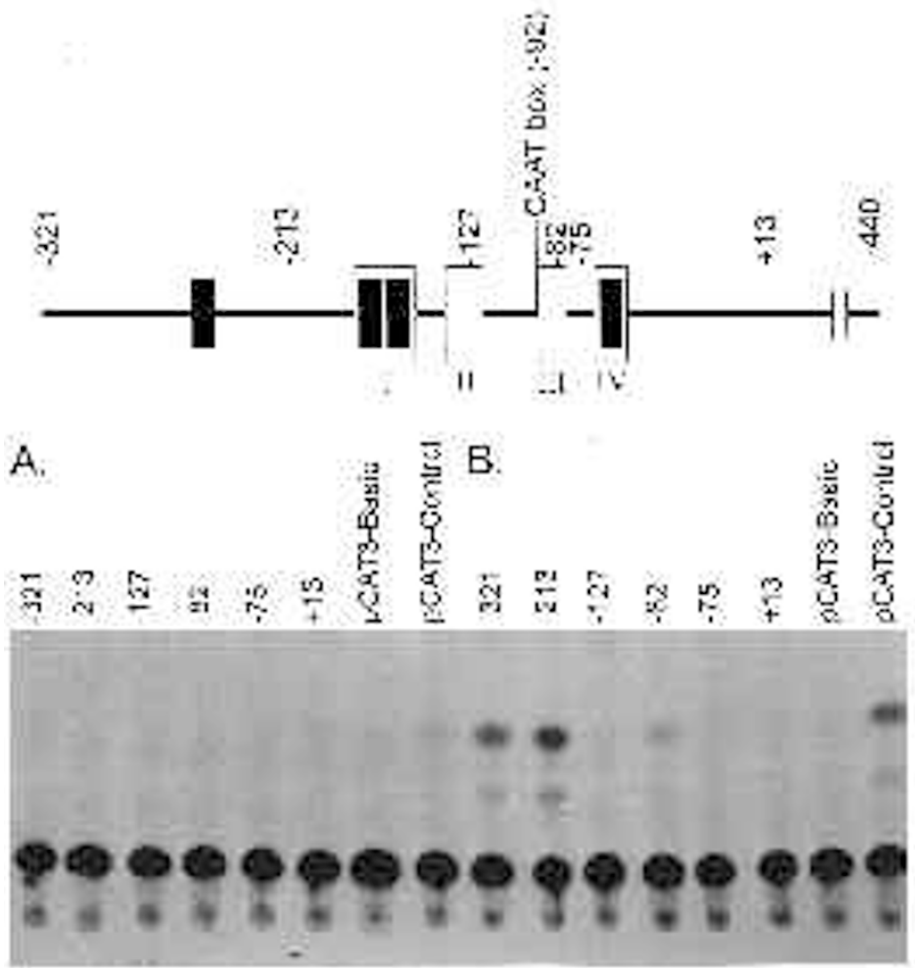

Figure 1. Activation of the ACL promoter by glucose. Transient transfection of deletion phACL plasmid constructs harboring the $\mathrm{ACL}$ promoters from indicated location of nucleotides from the transcription start sites to +440 was performed in Alexander cells. Diagrammatic presentation of the human ACL promoter was shown on the top. The open-boxes and filled-boxes indicate the putative $\mathrm{Sp} 1$ binding sites on DNA sequence analysis and the regions protected by purified human Sp1 on DNase I footprinting experiments. After transfection, cell extracts prepared from the cells cultured in the medium lacking glucose $(A)$ or in the medium containing $25 \mathrm{mM}$ glucose (B) for $48 \mathrm{~h}$, were assayed for CAT activity by thin-layer chromatography. The results shown were the representatives of more than three experiments. The statistical analysis was omitted due to the undetectable activities of promoter-constructs when cells were cultured in glucose-deficient medium. 
promoter activity was exerted by the ACL-CAT construct containing the region from -82 (data not shown). When the region from -82 to -76 were deleted from the clone pACL-82, promoter activity was decreased to near basal level as driven by pCAT3-Basic vector harboring neither promoter nor enhancer element.

When Alexander cells were cultured in RPMI medium 1640 lacking glucose, promoter activity of all constructs was abolished (Figure 1A). However, treatment of the cells with glucose $(25 \mathrm{mM})$ activated the ACL promoter spanning from -213 to +440 (pACL213) (Figure 1B). Interestingly, the ACL promoter-CAT construct harboring -321 to +440 (pACL-321) showed lower activity than pACL-213, suggesting that some repressive elements reside on the promoter region from 321 to -213 . However, the induction of ACL promoter

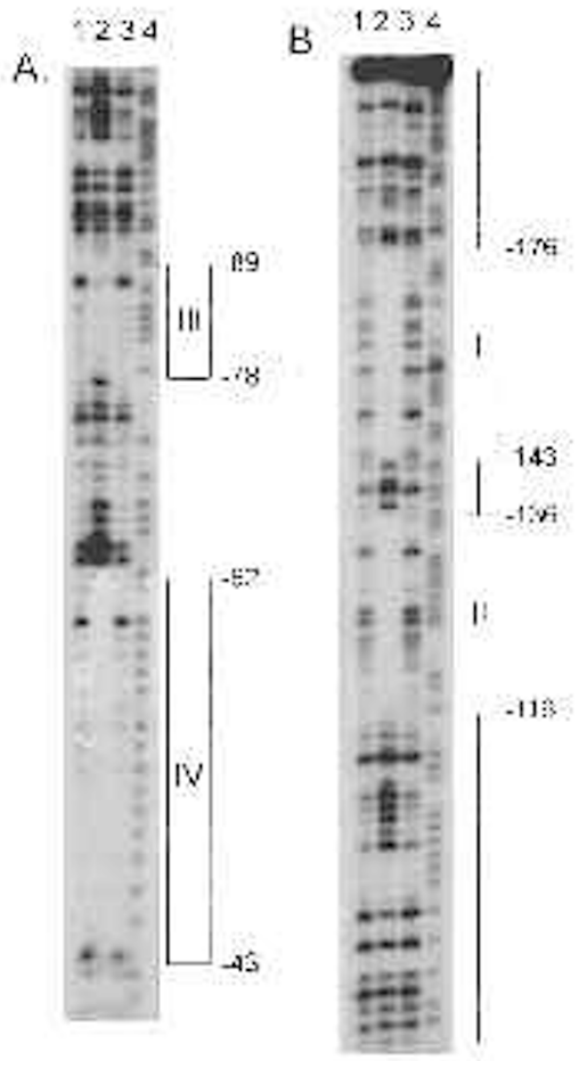

Figure 2. DNase I footprinting of the human ACL promoter (-213 to -17) by human Sp1. DNA fragment -213 to -17 was purified by digestion of phACL-213 with Kpnl and $\mathrm{BamHI}$, and labeled with ${ }^{32} \mathrm{P}$ to generate the labeled coding strands. The probe was incubated with 1 footprinting unit of human Sp1 protein (lane 2) and digested with DNase I as described in 'Materials and Methods'. Lane 1 and 3 represent the free probe DNA. Lane 4 represents the DNA size marker generated by Maxam and Gilbert sequencing of the same probe. Boxes with their nucleotide numbers represent the locations of the protected regions on the right side of each panel. Panel $B$ represents the result of extended development of panel $A$ for enhanced resolution. activity by glucose was completely vanished by deleting the promoter region from -213 to -128 . These results indicate that promoter elements responsible for glucose-responsiveness may reside in the nucleotides from -213 to -128 of the ACL promoter.

\section{Sp1 binding sites reside in the ACL promoter}

Based on the DNA sequence analysis (Park et al., 1997), the primary target of transcription factors to mediate the basal activity and the induction of the ACL promoter by glucose was focused on transcription factor Sp1. To identify Sp1 binding sites on the ACL promoter, the DNase I footprinting was performed using ${ }^{32} \mathrm{P}$-labeled ACL promoter fragments (Figure 2). Results from the DNase I footprinting assay showed that the ACL promoter from nucleotide -213 to -17 contained four Sp1 binding sites (nucleotide -176 to -145 : box I, -136 to -116 : box II, -89 to -78 : box III, and -62 to -43 : box IV). Box I and IV covers the expected consensus binding sites for Sp1 (GGG GCG GGG, Letovsky and Dynan, 1989), while, two protected regions, box II (GAA TTG GGA GGA GCC CTG GCG) and III (ATC GCG GGG CCG), revealed the novel sequences for Sp1 binding. In spite of the deviation from Sp1 consensus sequence, the sequences of box II and III were so GC-rich as to be postulated to bind the transcription factor Sp1 with weak affinity.

\section{Changes in binding ability of the transcription factors to ACL promoter by glucose}

Gel mobility shift assay was performed to evaluate the changes of expression of transcription factors driven by glucose. We synthesized both strands of oligonucleotides spanning from -179 to -141 and from -140 to -110 harboring box I and box II, respectively, shown on DNase I footprinting. The double-stranded oligonucleotides formed by annealing the respective single-stranded oligonucleotides were inserted into pT7-Blue T vector (Novagen) for restriction-digestion to produce the respective DNA fragments. After digestion with the appropriate restriction enzymes, the fragments were end-labeled with ${ }^{32} \mathrm{P}$ by Klenow enzyme, and gel-purified. The double-stranded oligonucleotides that contained box I and II basically revealed two major bands (band I with slower mobility, and band II with faster mobility) by reacting with the nuclear proteins extracted from the Alexander cells (Figure $3 \mathrm{~A})$. The formation of two major bands by labeled double-stranded oligonucleotides was completely competed with the unlabeled consensus oligonucleotide for Sp1 (ATT CGA TCG GGG CGG GGC GAG C, Promega) (Figure $3 A$, lane 4 and 5), while the unrelated oligonucleotide conferring TFIID did not affect the binding of nuclear extracts to probes (lane 6). In supershift assay, when the nuclear extracts were preincubated with antibody against purified human Sp1, the DNA-protein complex at band I with slower mobility decreased, resulting in formation of the additional band supershifted (lane 7). 


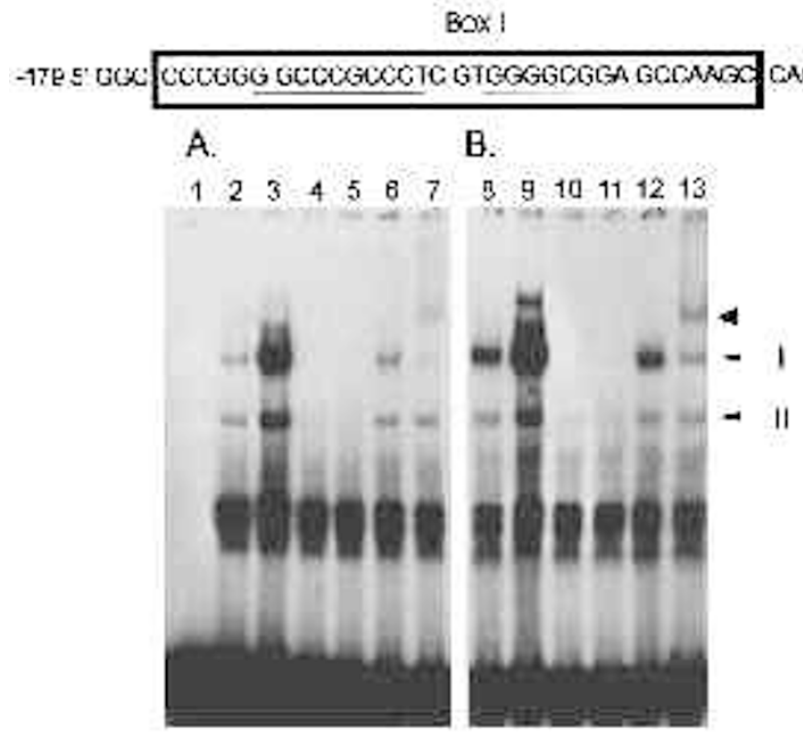

However, Sp1 antibody did not completely vanish band I, suggesting a binding probability of the other transcription factors to box I with similar sequence specificity. Band II was also competed with consensus oligonucleotides of Sp1; however, band II was not supershifted with antibody against Sp1, also suggesting the binding of transcription factors other than Sp1.

When the cells were incubated in the media with 25 $\mathrm{mM}$ glucose, the amount of band I was increased without change in band II (Figure 3B, lane 8 and 9). The increased band I by glucose attributed to the increased formation of the supershifted band by Sp1 antibody. The amount of remaining band I after supershift by Sp1 antibody was obviously increased when cells were incubated in the media containing glucose (Figure 3B, lane 13). These results suggest that transcription factor $\mathrm{Sp} 1$ may mediate the glucose-mediated activation of the ACL promoter by changing its expression in cells, albeit, the expression of other transcription factors with similar binding specificity are modulated by glucose. The probe containing box II sequence also showed two similar major bands shifted by nuclear proteins from control and induced Alexander cells (Figure 4). However, intensity of shifted band I and II was weaker than that of box I, and supershifting by Sp1 was not prominent. Incubation of cells in the media containing glucose resulted in decreased formation of band II (lane 8 and 9) compared to the amount of band II formed by nuclear proteins from control group. It suggests that transcription factors, of which the expression is decreased by glucose, other than Sp1 may participate in formation of band II, because band II was not super-shifted by Sp1 antibody.
Figure 3. Gel mobility shift assay of Alexander nuclear extracts with oligonucleotide harboring box I. Double-stranded oligonucleotide probes corresponding to -179 to -141 of the ACL promoter were ${ }^{32} \mathrm{P}$-end labeled and used in a gel mobility shift assay as described under 'Materials and Methods'. The probes were incubated in the absence (lane 1) or in the presence $1 \mu \mathrm{g}$ (lane 2 and 8 ) or $5 \mu \mathrm{g}$ (lane 3 and 9 ) of nuclear extracts from Alexander cells treated with (B) or without (A) glucose. For competition and supershift assay, unlabeled consensus oligonucleotide for Sp1 (Promega, lane 4 and 10, 20 pmoles; lane 5 and 11, 200 pmoles) and antibody against to human Sp1 (lane 7 and 13), respectively, were preincubated with nuclear extracts before adding the probes. Lane 6 and 12 show the result of competition with unlabeled consensus oligonucleotide for TFIID (Promega). The arrows and arrowhead indicate the positions of the major shifted bands and the band supershifted by Sp1 antibody, respectively. The consensus Sp1 binding sites are represented by underline and the actual protected region (box I) on DNase I footprinting is indicated by open box on the top of the figure.

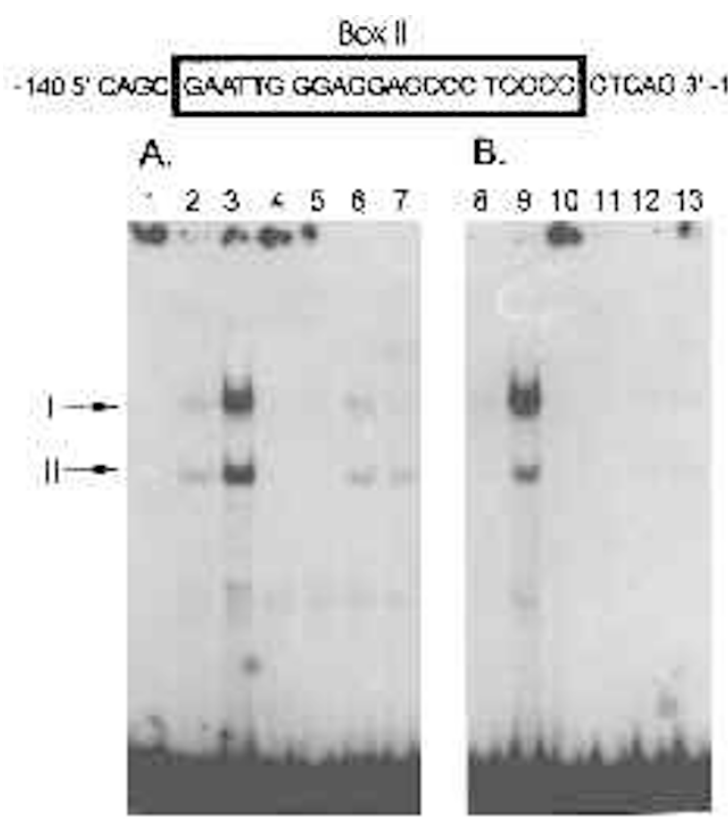

Figure 4. Gel mobility shift assays of Alexander nuclear extracts with oligonucleotide harboring box II. Double-stranded oligonucleotide probes corresponding to -140 to -110 of the ACL promoter were ${ }^{32} \mathrm{P}$-end labeled and used in a gel mobility shift assay as described under 'Materials and Methods'. The procedures of mobility shift assay are the same as in Figure 3. The arrows indicate the positions of the major shifted bands. The actual protected region (box II) on DNase I footprinting is indicated by open box on the top of the figure.

\section{Glucose changes the expression of Sp1-family transcription factors}

To evaluate the results from mobility shift assay, the 

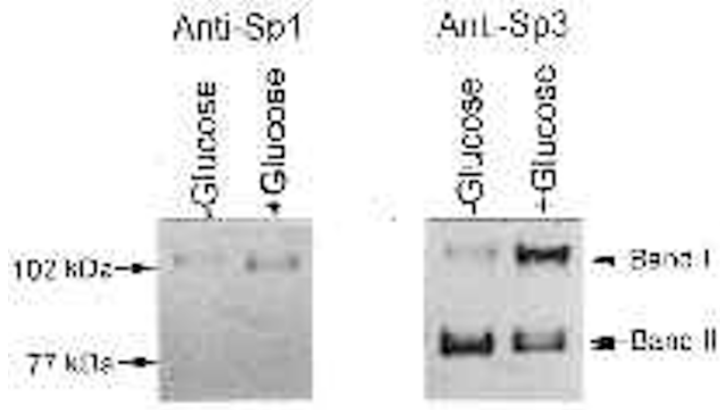

Figure 5. Western blot assays of Alexander nuclear extracts with antibody against Sp1 and Sp3. Nuclear proteins extracted from Alexander cells which were cultured in the medium lacking glucose (-Glucose) or containing $25 \mathrm{mM}$ glucose (+Glucose) were subjected to SDS-polyacrylamide gel electrophoresis. Western blot assay were performed using antibody antibody against Sp1 (A) and Sp3 (B). Positions of the three species of Sp3 (band II and I) are indicated. Molecular weight markers are indicated on the left.

possibility of transcription factors other than Sp1 was primarily confined to the Sp1-family transcription factors. Nuclear proteins extracted from the Alexander cells treated with glucose were immunoblotted with antibody against Sp1 or Sp3. The immunoblotting with Sp1 anti-body showed single bands of about $100 \mathrm{kDa}$ (Figure 5A). The amount of Sp1 increased by glucose in accordance with the results shown on gel mobility shift assay. More prominently, three bands were detected by antibody against Sp3 (Figure 5B). The estimated molecular sizes of the band with slower mobility and duplex bands with faster mobility were about 110 and $80 \mathrm{kDa}$, respectively. This result is in accordance with the results of Kennett et al. (1997). When the cells were treated with glucose, the immunoblot with Sp3 antibody showed prominent increase in the band of $110 \mathrm{kDa}$, with decreased amount of the bands of about $80 \mathrm{kDa}$ (Figure $5 \mathrm{~B})$. These results suggest that expression of $\mathrm{Sp} 1$ and Sp3 is modulated by glucose, and that change in expression of Sp3 - increase in $110 \mathrm{kDa}$ isoform and decrease in two isoforms of about $80 \mathrm{kDa}$ - may be an important regulator in activating the $A C L$ promoter by glucose.

\section{Discussion}

$\mathrm{ACL}$, an enzyme catalyzing the first step in cellular biosynthesis of fatty acids, is induced in the presence of high glucose levels. In the Alexander cell, the region -213 to -128 of the ACL promoter responsible for conferring glucose-mediated transcription contains one Sp1 binding site (box I) determined by DNase I footprinting assay and sequences flanking a part of the second Sp1 binding site. The sequences of these regions were not expected to play a critical role in glucose responsiveness because any putative glucose response element previously reported were not revealed on DNA sequence analysis.

Sp1 was one of the first eukaryotic transcription factors to be identified and cloned as a factor that binds to the SV40 early promoter (Dynan and Tjian, 1983). It contains three zinc finger motifs, Cys-2-His-2, which bind to a consensus GGG GCG GGG (Letovsky and Dynan, 1989). Sp1 is an abundant nuclear protein in most cells, but the level of expression changes during development and varies in different cell types (Saffer et al., 1991). $\mathrm{Sp} 1$ is the founding member of a growing family of proteins with highly homologous zinc-finger domains that bind GC or GT boxes (Hagen et al., 1992; Imataka et al., 1992; Kingsley and Winoto, 1992; Miller and Bieker, 1993; Crossley et al., 1996).

Gel mobility shift assay showed two specific DNAprotein complexes. While the binding pattern of oligonucleotide -140 to -110 covering box II was not changed by glucose, the prominent increase in the DNA-protein complex with slower mobility (band I) was observed in oligonucleotide -179 to -141 . Competition gel shift assays and supershift assays have confirmed that this DNAprotein complex with slower mobility was the result of induced Sp1 by glucose. However, antibody against Sp1 did not completely supershift band I, suggesting that another member of transcription factors with a similar binding specificity takes part in the mediation of glucose induction in the ACL promoter.

Several proteins with homology to Sp1 have been identified in a number of different systems (reviewed in Ref by Lania et al., 1997). Among the members of Sp1 family proteins, Sp3 and Sp3-derived proteins were considered to stimulate or repress transcription of several genes (Kennett et al., 1997). In Western blot analysis, expression of $110 \mathrm{kDa}$ Sp3 was dramatically increased by glucose, while isoforms of Sp3 with $80 \mathrm{kDa}$ was decreased in its expression. Transcription factor Sp1 was also increased by glucose. However, the relative significance of increase in Sp1 expression is under evaluation. Considering 78-80 kDa Sp3-derived proteins could behave as potent inhibitors of Sp1/Sp3-mediated transcription, we predict that increase in expression of $110 \mathrm{kDa}$ Sp3 is the most important regulator in activation of the ACL promoter by glucose, while inhibitory effects of $78-80 \mathrm{kDa}$ Sp3 proteins were repressed. Functional studies on these Sp3-related proteins and another coregulators interacting with $\mathrm{Sp} 1$ family proteins for the ACL promoter to respond to glucose are currently ongoing.

\section{Acknowledgement}

The authors wish to acknowledge the financial support of the Korea Research Foundation made in the program year of 1997. 


\section{References}

Bradford M. M. (1976) A rapid and sensitive method for the quantitation of microgram quantities of protein utilizing the principle of protein-dye binding. Anal. Biochem. 72 : 248-264

Crossley, M., Whitelaw, E., Perkins, A., Williams, G., Fujiwara, Y. and Orkin, S. H. (1996) Isolation and characterization of the CDNA encoding BKLF/TEF-2, a major CACCC-box-binding protein in erythroid cells and selected other cells. Mol. Cell. Biol. 16: $1695-1705$

Dignam, J. D., Lebovitz, R. M. and Roeder, R. G. (1983) Accurate trans-cription initiation by RNA polymerase II in a soluble extract from isolated mammalian nuclei. Nucleic Acids Res. 11: 1475-89

Dynan, W. S. and Tjian, R. (1983) Isolation of transcription factors that discriminate between different promoters recognized by RNA polymerase II. Cell 32: 669-680

Hagen, G., Muller, S., Beato, M. and Suske, G. (1992) Cloning by recog-nition site screening of two novel GT box binding proteins: a family of Sp1 related genes. Nucleic Acids Res. 20: 5519-5525

Imataka, H., Sogawa, K., Yasumoto, K., Kikuchi, Y., Sasano, K., Kobayashi, A., Hayami, M. and Fujii-Kuriyama, Y. (1992) Two regulatory proteins that bind to the basic transcription element (BTE), a GC box sequence in the promoter region of the rat P-4501A1 gene. EMBO J. 11: 3663-3671

Katsurada, A., Iritani, N., Fukuda, H., Matsumura, Y., Nishimoto, N., Noguchi, T. and Tanaka, T. (1990a) Effects of nutrients and hormones on trans-criptional and posttranscriptional regulation of fatty acid synthase in rat liver. Eur. J. Biochem. 190: 427 433

Katsurada, A., Iritani, N., Fukuda, H., Matsumura, Y., Nishimoto, N., Noguchi, T. and Tanaka, T. (1990b) Effects of nutrients and hormones on trans-criptional and posttranscriptional regulation of acetyl CoA carboxylase in rat liver. Eur. J. Biochem. 190: $435-441$

Kennett, S. B., Udvadia, A. J. and Horowitz, J. M. (1997) Sp3 encodes multiple proteins that differ in their capacity to stimulate or repress trans-cription. Nucleic Acids Res. 25 3110-3117

Kim, K. S., Park, S. W. and Kim, Y. S. (1992a) Regulation of ATP-citrate lyase at transcriptional and post-transcriptional levels in rat liver. Biochem. Biophys. Res. Commun. 189: 264-271

Kim, K. S., Park, S. W. and Kim, Y. S. (1992b) Regulation of fatty acid synthase at transcriptional and post-transcriptional levels in rat liver. Yonsei Med. J. 33: 199-208 Kim, K. S., Park, S. W., Moon, Y. A. and Kim, Y. S. (1994) Organization of the 5 ' region of the rat ATP-citrate lyase gene. Biochem. J. 302: 759-764

Kingsley, C. and Winoto, A. (1992) Cloning of GT box-binding proteins: a novel Sp1 multigene family regulating T-cell receptor gene expression. Mol. Cell. Biol. 12: 42514261

Kornacker, M.S. and Lowenstein, J. M. (1965) Citrate and conversion of carbohydrate into fat. Biochem. J. 95: 832-837

Laemmli, U. K. (1970) Cleavage of structural proteins during the assembly of the head of bacteriophage T4. Nature 227: 680-685

Lania, L., Majelllo, B. and Luca P. D. (1997) Transcriptional regulation by the Sp family proteins. Int. J. Biochem. Cell Biol. 29: 1313-1323

Letovsky, J. and Dynan, W. S. (1989) Measurement of the binding of transcription factor Sp1 to a single GC box recognition sequence. Nucleic Acids Res. 17: 2639-2653

Maxam, A. and Gilbert, W. (1980) Sequencing end-labeled DNA with base-specific chemical cleavages. Methods Enzymol. 152: 721-735

Miller, I. J. and Bieker, J. J. (1993) A novel, erythroid cell-specific murine transcription factor that binds to the CACCC element and is related to the Kruppel family of nuclear proteins. Mol. Cell. Biol. 13: 2776-2786

Park, S. W., Moon, Y. A., Kim, K. S., Ahn, Y. H., and Kim, Y. S. (1997) Cloning and characterization of the 5 ' flanking region of human ATP-citrate lyase. Biochim. Biophys. Acta. 1353: 236-240

Pearce, N. J., Yates, J. W., Berkhout, T. A., Hackson, B., Tew, D., Boyd, H., Camiller, P., Sweeney, P., Gribble, A. D., Shaw, A. and Groot, P. H. E. (1998) The role of ATP 